\title{
Familial pituitary apoplexy as the only presentation of a novel AIP mutation
}

\section{Dear Editor}

Growth hormone (GH)-producing tumors in AIP mutation-positive patients are typically more aggressive than their sporadic counterparts. They are also frequently associated with onset in childhood and adolescence and appear to be less responsive to medical therapy (Beckers et al. 2013). A male predominance has been observed (Daly et al. 2010). We report on a unique clinical presentation of a kindred with a novel AIP mutation: only one of the three affected members had all the typical signs and symptoms of patients with an AIP mutation. On the contrary, the carrier father and brother had both partially empty sella turcica and, in fact, the latter ended being treated for anterior pituitary lobe hormonal deficiencies, including GH. This was presumably the result of pituitary apoplexy due to a rapidly growing AIP-induced adenoma.

Briefly, a 12 years 2 month-old boy was seen for tall stature and accelerated growth velocity that was first noticed at the age of 4 years. At initial presentation, his height was $186.6 \mathrm{~cm}$ ( $z$-score +4.72$)$, over the calculated mid-parental height $(180.5 \pm 4.5 \mathrm{~cm})$, and his weight was $78.7 \mathrm{~kg}$ ( $z$-score +2.59$)$. He was also macrocephalic and he had several facial characteristics typical of gigantism. Hormonal investigation showed increased IGF1: $906 \mathrm{ng} / \mathrm{ml}$ (nv: 183-850) and GH: $18.3 \mathrm{ng} / \mathrm{ml}$ that $\mathrm{did}$ not suppress to oral glucose tolerance test (OGTT). The rest of pituitary hormones were in the lower normal range (Supplementary Table 1, see section on supplementary data given at the end of this article). Pituitary MRI showed the presence of a $1.3 \times 1.2 \times 1.1 \mathrm{~cm}$ pituitary adenoma with suprasellar extension (Fig. 1A). He underwent partial resection of the pituitary adenoma. The surgical pathology evaluation confirmed the presence of a GH-positive, sparsely granulated tumor with globules of keratin (fibrous bodies) and lack of normal reticulin framework (Fig. 2A, B, C, and D). Areas of expanded acini clearly distinctive from the adenoma were detected suggestive of hyperplasia (Fig. 2E and F). Both parents had normal heights and no history of acromegaly.
A paternal uncle, however, had a history of acromegaly secondary to a GH-producing pituitary adenoma that had been operated in the distant past. Genetic analysis for mutations in MEN1 and CDKN1B genes was negative, whereas a $G$ deletion in exon 1 of AIP gene, not previously reported, which creates a premature stop codon 16 amino acids downstream (c.4delG/p.A2Rfs*16), was detected. The same mutation was detected in his clinically unaffected 41-year-old father, his younger brother, and seven other family relatives from the paternal side. The median age of the seven family members that were tested positive for the same mutation was 27 years (age range 6 months to 65 years).

None of them had a history of a GH-producing pituitary adenoma or any symptoms related to $\mathrm{GH}$ (or PRL) excess. Appropriate instructions were given for further biochemical and imaging investigation, which to this day has not been completed for all family members. The paternal uncle refused testing. Western blot of extracts from the patient's pituitary tumor cells showed almost no expression of AIP compared with another patient with acromegaly without an AIP mutation (Fig. 2G). The patient was placed on SST. At 2 years postoperatively, he had normal basic GH and IGF1 levels and adequate suppression of GH levels to OGTT. No deficiencies of the other pituitary hormonal levels were detected (Supplementary Table 1).

The 41-year-old father and the 8 years 6 month-old brother of the proband were evaluated for the presence of a pituitary adenoma since they were found to harbor the same mutation as the patient. The father's only symptom was decreased libido. Pituitary and target gland hormones were found to be in the lower quartile of the respective normal ranges. Pituitary MRI showed presence of a left-sided $4.3 \times 4 \times 3 \mathrm{~mm}$ hypoenhancing area; the small pituitary tissue was peripherally located and the overall image was typical of a partially empty sella turcica (Fig. 1B).

Published by Bioscientifica Ltd. 

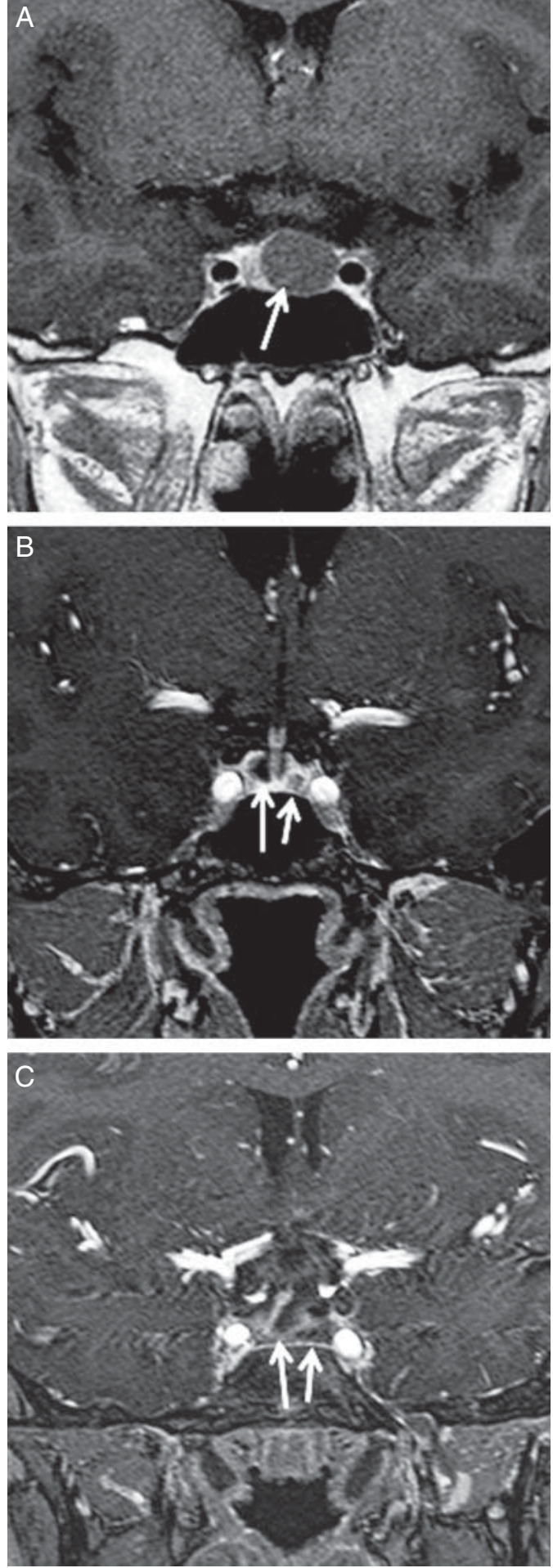

Figure 1

(A) Pre-contrast coronal T1-weighted pituitary MRI showing a macroadenoma with suprasellar extension (arrow). Post-contrast coronal T1-weighted pituitary MRI from proband's father (B) and younger brother (C), showing a subtle left hypoenhancing area (possibly a microadenoma) (small arrow) and partially empty sella (large arrow).
Review of the systems of patient's younger brother did not reveal any symptoms related to a hormone-secreting pituitary tumor but a reduced annual growth rate $(2 \mathrm{~cm} /$ year for the last 2 years) was noted. His height was $136.8 \mathrm{~cm}$ (z-score: 1.6$)$ and his weight was $35.8 \mathrm{~kg}$ (z-score: 1.8 ) and he, unlike his brother, was normocephalic. Hormonal investigation was consistent with partial hypopituitarism. Pituitary MRI findings were similar to those detected in his father (Fig. 1C). The patient was started on hydrocortisone, levothyroxine, and GH replacement.

Familial empty sella turcica in the context of an AIP mutation is a novel phenotype for patients with AIP mutations. There are two other reports (Villa et al. 2011, Dal et al. 2012) that demonstrate that rapid growth of an AIP loss-induced tumor may also lead to apoplexy before a hormonal syndrome becomes clinically detectable. In one of them, like in our case, pathological examination revealed multiple areas of pituitary hyperplasia along with the adenomatous tissue, which stained positively for $\mathrm{GH}$, indicating somatotroph hyperplasia (Villa et al. 2011).

Subclinical pituitary apoplexy is not extraordinarily rare. This term has been used to describe cases of pituitary hemorrhages and infarctions detected incidentally on routine radiological studies, which are typically associated with mild symptoms or may even remain completely asymptomatic (Findling et al. 1981, Ostrov et al. 1989). In a retrospective review of 560 cases of pituitary adenoma, 93 tumors (16.6\%) showed evidence of intratumoral hematoma, yet only 38 patients (6.8\%) experienced an apoplectic event (Wakai et al. 1981). Mohr \& Hardy (1982) reviewed 664 patients operated for pituitary adenomas over a period of 17 years. Classic apoplexy with the typical presentation was seen only in four patients (0.6\%). However, 64 patients (9.6\%) had evidence of hemorrhage or necrosis at surgery (Mohr \& Hardy 1982). In addition, Yoshino et al. (2005) described two cases of nonfunctioning pituitary adenomas that underwent complete resolution through asymptomatic necrosis with the only finding being an empty sella on pituitary MRI.

Our unique case report provides new data for what appears to be a new phenotype for AIP mutation-positive patients: apoplexy and consequently pituitary deficiency (rather than hormone excess). If the index case had not manifested the full-blown acromegalic symptoms, the whole family would have probably remained undiagnosed. This suggests that the prevalence of the AIP mutations in FIPA kindreds may be higher than that reported in the literature (Beckers et al. 2013). It also indicates that the empty sella syndrome and/or apoplexy is one of the possible phenotypes of AIP defects.

Published by Bioscientifica Ltd 

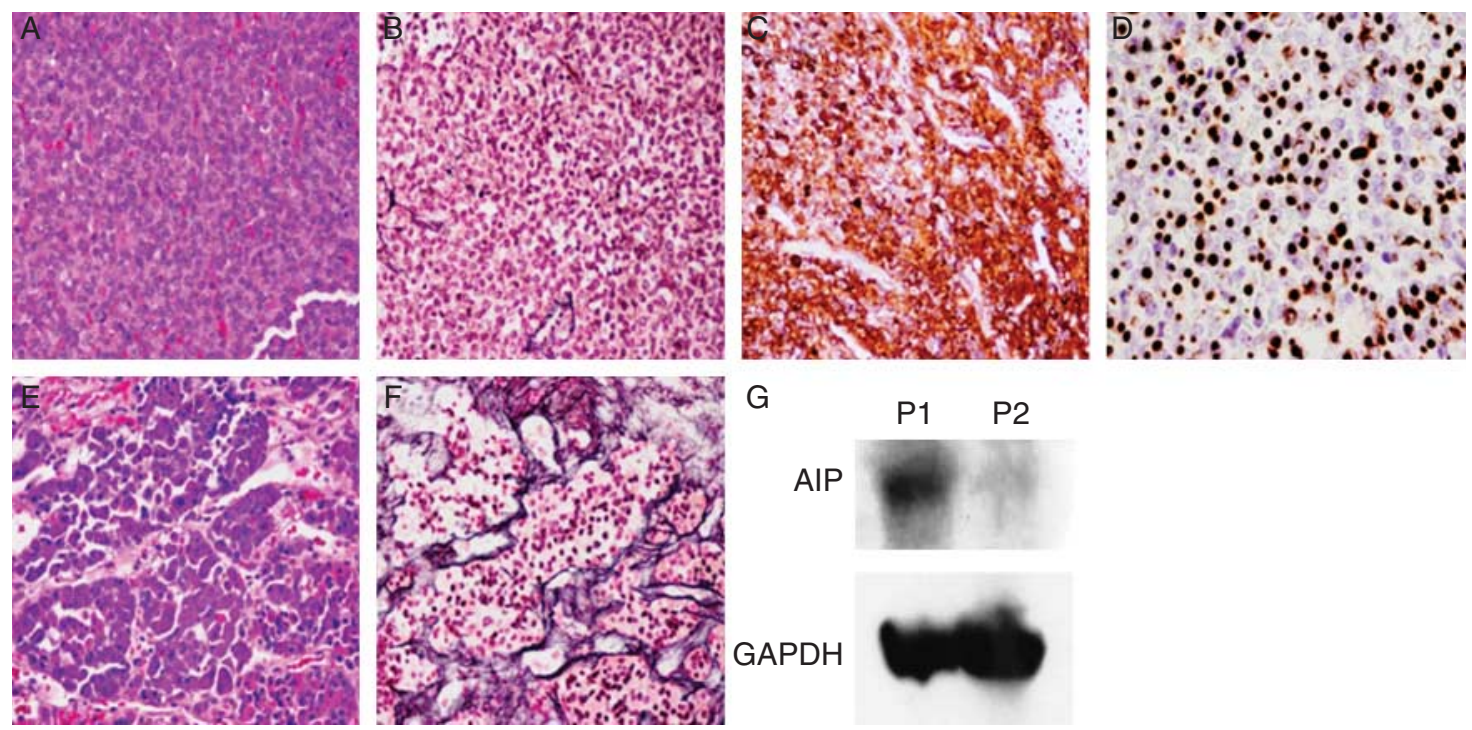

G

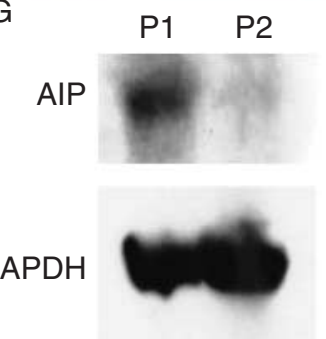

\section{Figure 2}

Pituitary adenoma with proliferation of monotonoues cells ( $A$, H\&E 20X) with breakdown of reticulin framework (B, reticulin stain $20 \times$ ), diffuse staining for hGH (C, hGH stain $20 \times$ ), and with characteristic juxtanulear globular positivity corresponding to fibrous bodies (D, Cam 5.2, 40×).

Although no widely accepted guidelines for the clinical management of AIP mutation-positive families are available, baseline MRI and yearly screening for abnormal pituitary function have been proposed (Trivellin \& Korbonits 2011, Beckers et al. 2013). This appears to be a reasonable approach, although one should add global pituitary function screening to include biochemical signs of subtle or partial hypopituitarism.

\section{Paraskevi Xekouki ${ }^{1}$ Spyridon A Mastroyiannis ${ }^{1}$ Dimitrios Avgeropoulos ${ }^{1}$ Maria de la Luz Sierra ${ }^{1}$ Giampaolo Trivellin ${ }^{1}$ Evgenia A Gourgari ${ }^{1}$ Charalampos Lyssikatos ${ }^{1}$ Martha Quezado ${ }^{2}$ Nicholas Patronas ${ }^{3}$ Christina Kanaka-Gantenbein ${ }^{4}$ George P Chrousos ${ }^{4}$ Constantine A Stratakis ${ }^{1}$}

${ }^{1}$ Section on Endocrinology and Genetics, Program on Developmental Endocrinology and Genetics (PDEGEN) and Pediatric Endocrinology Inter-institute Training Program, Eunice Kennedy Shriver National Institute of Child Health and Human Development (NICHD), National Institutes of
The adjacent anterior pituitary shows expanded acini on HE (E, H\&E 20X); reticulin stain highlight preserved reticulin fibers $(F, 20 \times)$. (G) Western blot of AIP expression in a patient with acromegaly without AIP mutation (P1) and in our patient with the AIP mutation (P2).

Health (NIH), NIH-Clinical Research Center, 10 Center Drive, Building 10, Room 1-3330, MSC1103, Bethesda, Maryland, 20892, USA ${ }^{2}$ Laboratory of Pathology, National Cancer Institute, National Institutes of Health (NIH), Bethesda, Maryland, 20892, USA

${ }^{3}$ Department of Diagnostic Radiology, National Institutes of Health (NIH), Clinical Research Center, Bethesda, Maryland, 20892, USA

${ }^{4}$ Endocrine Unit, First Department of Pediatrics, 'Aghia Sophia' Children's Hospital, University of Athens, Athens, Greece

(Correspondence should be addressed to C A Stratakis); email: stratakc@mail.nih.gov

\section{Supplementary data}

This is linked to the online version of the paper at http://dx.doi.org/10.1530/ ERC-13-0218.

\section{Declaration of interest}

The authors declare that there is no conflict of interest that could be perceived as prejudicing the impartiality of the research reported.

\section{Funding}

This study was supported by the NIH Intramural Research Program of the Eunice Kennedy Shriver National Institute of Child Health and Human Development (NICHD).

Published by Bioscientifica Ltd. 


\section{Author contribution statement}

The contribution of each authors is as follows: $\mathrm{P}$ Xekouki performed most of the experiments described in the manuscript and prepared the manuscript. S A Mastroyiannis and D Avgeropoulos participated in the genetic testing and analysis of the described kindred. $M$ de la Luz Sierra prepared the clinical specimens for genetic analysis. G Trivellin participated in manuscript preparation and editing. E A Gourgari was the physician who took care of the described kindred at the NIH. C Lyssikatos collected clinical specimen. $M$ Quezado involved in pathology evaluation and immunohistochemistry studies. N Patronas involved in reading and interpretation of imaging studies. C Kanaka-Gantenbein was the primary care physician of the described kindred. G P Chrousos was the physician who originally identified and referred the family to the NIH. C A Stratakis was the senior investigator at NICHD, which provided most of the funding for this project under the NIH Intramural Research Program, and overall supervised the experiments, presentation of results, design of figures, and writing the manuscript.

\section{References}

Beckers A, Aaltonen LA, Daly AF \& Karhu A 2013 Familial isolated pituitary adenomas (FIPA) and the pituitary adenoma predisposition due to mutations in the aryl hydrocarbon receptor interacting protein (AIP) gene. Endocrine Reviews 34 239-277. (doi:10.1210/er.2012-1013)

Dal J, Gravholt C, Gaustadnes M \& Jørgensen JO 2012 Acromegaly Associated with an AIP Mutation but without an Overt Pituitary Adenoma. A Case Report. Abstracts 15th Congress of the European Neuroendocrine Association 2012, Vienna, Austria, Austrian. Journal of Clinical Endocrinology and Metabolism 538 (available at: http://www. kup.at/kup/pdf/10856.pdf)
Daly AF, Tichomirowa MA, Petrossians P, Heliövaara E, Jaffrain-Rea ML, Barlier A, Naves LA, Ebeling T, Karhu A, Raappana A et al. 2010 Clinical characteristics and therapeutic responses in patients with germ-line AIP mutations and pituitary adenomas: an international collaborative study. Journal of Clinical Endocrinology and Metabolism 95 E373-E383. (doi:10.1210/jc.2009-2556)

Findling JW, Tyrrell JB, Aron DC, Fitzgerald PA, Wilson CB \& Forsham PH 1981 Silent pituitary apoplexy: subclinical infarction of an adrenocorticotropin-producing pituitary adenoma. Journal of Clinical Endocrinology and Metabolism 52 95-97. (doi:10.1210/jcem-52-1-95)

Mohr G \& Hardy J 1982 Hemorrhage, necrosis and apoplexy in pituitary adenomas. Surgical Neurology 18 181-189. (doi:10.1016/00903019(82)90388-3)

Ostrov SG, Quencer RM, Hoffman JC, Davis PC, Hasso AN \& David NJ 1989 Hemorrhage within pituitary adenomas: how often associated with pituitary apoplexy syndrome? AJR. American Journal of Roentgenology 153 153-160. (doi:10.2214/ajr.153.1.153)

Trivellin G \& Korbonits M 2011 AIP and its interacting partners. Journal of Endocrinology 210 137-155. (doi:10.1530/JOE-11-0054)

Villa C, Lagonigro MS, Magri F, Koziak M, Jaffrain Rea ML, Brauner R, Bouligand J, Junier MP, Di Rocco F, Sainte-Rose C et al. 2011 Hyperplasia-adenoma sequence in pituitary tumorigenesis related to aryl hydrocarbon receptor interacting protein (AIP) gene mutation. Endocrine-Related Cancer 18 347-356. (doi:10.1530/ERC-11-0059)

Wakai S, Fukushima T, Teramoto A \& Sano K 1981 Pituitary apoplexy: its incidence and clinical significance. Journal of Neurosurgery 55 187-193. (doi:10.3171/jns.1981.55.2.0187)

Yoshino A, Katayama Y, Watanabe T \& Hirota H 2005 Vanishing pituitary mass revealed by timely magnetic resonance imaging: examples of spontaneous resolution of nonfunctioning pituitary adenoma. Acta Neurochirurgica 147 253-257. (doi:10.1007/s00701-004-0443-9)

Received in final form 19 August 2013

Accepted 20 August 2013
(C) 2013 Society for Endocrinology Printed in Great Britain
Published by Bioscientifica Ltd 